\title{
Optimisation of Carbonation Reactor Design Using Multiphysics Models for Precipitated Calcium Carbonate PCC Production
}

\author{
Yousra Hayder Mohmmed Elzaki \\ Lecturer, Agricultural and Biological Engineering Department, Faculty of Engineering, University of Khartoum, 11111 \\ Khartoum, Sudan
}

\begin{abstract}
Temperature distributions in the carbonation reactor with an inner diameter of $4.23 \mathrm{~m}$ and overall length of $7 \mathrm{~m}$ is numerically modelled. This is motivated by the need to lower overall capital and operating costs, and to optimise the carbonation process performance, simultaneously. In this paper, computational simulations are used to design an industrial scale carbonation reactor $89.72 \mathrm{~m}^{3}$ consisting of an external cooling jacket. Several parameters are varied including reactor's geometry (6 shapes), wall thickness $(100,200$, and $300 \mathrm{~mm})$, cooling jacket temperature $\left(15,25\right.$, and $\left.35^{\circ} \mathrm{C}\right)$, and material type. These parameters are varied interchangeably to compare temperature probe plots at a point probe $(1.5,0)$ located closer to the cooling jacket region. Simulations in COMSOL $^{\circledR}$ Multiphysics 5.2a show that partial Carbon Steel AISI 4340 jackets with a $100 \mathrm{~mm}$ distance, between vessel wall and outside wall of jacket, while operating at ambient temperature range of $20-25^{\circ} \mathrm{c}$, can achieve the required operating temperature i.e. $50 \pm 5^{\circ} \mathrm{C}$. Then, the precipitation process of the calcium carbonate (PCC) is maximised. This result in decreased bare materials' capital costs by $95.87 \%$ and $97.39 \%$ compared to Nickel and Titanium, respectively. The need for cooling the water for the jacket is eliminated, while operating costs are lowered by $25-50 \%$ per $10^{\circ} \mathrm{C}$. A simplified experimental set-up is proposed to demonstrate the coupling of $\mathrm{COMSOL}^{\circledR}$ simulations with experimental work can be a reliable and an effective method to evaluate the carbonation reactor model design.
\end{abstract}

Keywords: $\quad$ Carbonation, $\quad \mathrm{COMSOL}^{\circledR}, \quad$ Multiphysics, Optimisation, Temperature, Distribution.

\section{INTRODUCTION}

Mineral carbonation is considered as an important form of Carbon Dioxide $\left(\mathrm{CO}_{2}\right)$ capture that allows conversion of $\mathrm{CO}_{2}$ into stable precipitate $[1,2] . \mathrm{CO}_{2}$ in-situ mineralisation was found to be environmentally friendly, economically feasible, permanent, and one of the most applicable techniques for large and point source $\mathrm{CO}_{2}$ emission sites i.e. steel manufacturing plants, compared to injection of supercritical $\mathrm{CO}_{2}$ into geological formations [3]. An average of 350 to $400 \mathrm{~kg}$ per tonne of steel (crude steel production worldwide is 1629.60 Mt in 2016), of solid alkaline steel slag is formed, it contains different elements such as calcium and magnesium in oxide forms [4-6]. However, steel slag-solid wastes have restricted capacity for carbon sequestration, as they have limited amounts of available metal oxides for the carbonation process compared to natural minerals. This requires pre-treatment of the slag aggregate surface (i.e. calcium extraction using Ammonium Chloride $\mathrm{NH}_{4} \mathrm{Cl}$ ) to maximize the carbonation process yield [3]. From a sustainable point of view, the use of steel slag by-products at source points alleviates cost effective carbon sequestration, help protect the environment by adding a further carbon sink, and reduce spreading of harmful contaminants from dumps [6].

Researchers have investigated several options of carbonation reactors for steel slag, such as Basic Oxygen Steelmaking (BOS) slag. The most common reactor types were batch and semi continuous reactors including packed columns, bubbled columns with stirring, and spray towers [4,7]. Basic Oxygen Furnace (BOF) slag was used with wastewaters from a cold rolling process as a solvent to reduce the alkalinity of both the slag and the waters, respectively, as discussed by Chang [7]. A rotating packed bed reactor was utilized to enhance mass transfer to create a kinetic model for the reaction rate. The highest carbonation conversion achieved was $90.7 \%$ at ambient operating conditions (1atm, $25^{\circ} \mathrm{C}$ ) [7]. Bang [8], studied the use of a micro bubble generator that has a nozzle system for pumping gas and aqueous solution simultaneously. The reaction time was reduced by $50 \%$ compared to a conventional frit bubble reactor. A cooling reservoir was used at $4^{\circ} \mathrm{C}$ to exchange heat with the reactor. It was shown that the temperature difference decreases as the reactor proceeds; due to the decreased rate of precipitation rates. However, the coolant type and operating temperature and other conditions were not further explained, and the detailed design was not presented either. A bubble column and high gravity rotating reactors were used to study the effect of 
various dispersion agents on the morphology of Precipitated Calcium Carbonate PCC. A temperature range of $25-35^{\circ} \mathrm{C}$ and reaction time between $20-40 \mathrm{~min}$ was used in the experiments. The reaction operating conditions and their effects on the PCC yield were not discussed [4].

Most of these experiments' focus is $\mathrm{CO}_{2}$ capture. Also, Calcium Carbonate precipitation is found to cause operational issues in most of the previously mentioned reactor types, such as difficulties in services and cleaning of i.e. spray towers. In this study, the focus is producing PCC of certain requirements in terms of morphology and quality to meet certain specifications (BS EN ISO 3262-6:1998), with cautious control of operating temperature, residence time, coolant flow,

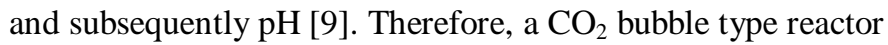
with a stirrer was used to precipitate Calcium Carbonate. Researchers have investigated the kinetic behaviour of different species $\left(\mathrm{Ca}, \mathrm{Mg}, \mathrm{CO}_{2}, \mathrm{H}_{2} \mathrm{O}, \mathrm{CO}_{3}{ }^{-2}, \mathrm{HCO}^{3-}\right.$ or $\mathrm{NH}_{3}$ ) in the carbonation process, and the influence of key operating parameters i.e. liquid-to-solid $\mathrm{L} / \mathrm{S}$ ratios, temperature, pressure, $\mathrm{pH}$, initial $\mathrm{Ca}^{2+}$ and ammonia concentrations, on carbonation rates and yields. The need that motivates it is to enhance the carbonation process kinetically and economically under ambient temperature and pressure, by controlling the reaction parameters [1]. Atmospheric pressure (1atm) was found to be the optimal condition for higher carbonation conversions, in a $\mathrm{pH}$-swing process using $\mathrm{NH}_{4} \mathrm{Cl}$, for $30 \mathrm{~min}$ or longer reactions (as an extraction agent). Also, several experiments showed that $50^{\circ} \mathrm{C}$ is the most favorable temperature range for $\mathrm{CaCO}_{3}$ precipitation. Higher temperatures increase $\mathrm{Ca}$ ions leaching, but decrease the solubility of $\mathrm{CO}_{2}$, hence, the precipitation reaction is delayed. However, the optimum temperature is highly dependent on the slag properties and the specific conditions of the experiments conducted [2, 3, 9-11].

COMSOL $^{\circledR}$ Multiphysics is a powerful computational software that deploys Finite Elements (FE) with multiple engineering applications and ability to couple physics. This makes COMSOL ${ }^{\circledR}$ very appealing for reactors' simulations and design. A $3 \mathrm{D}$ model for a $22 \mathrm{MW}_{\text {th }}$ multipurpose research reactor was modelled to study the neutronic behaviour at different experimental scenarios. Reactor physics parameters such as criticality and excess reactivity were found to be in good agreement with experimental results [12]. Another neutronic study involved coupling of transient heat transfer, hydrodynamics, and neutronics to analyse effects of several parameters on an $85 \mathrm{MW}_{\text {th }}$ research reactor [13]. Pressure drop and velocity profiles were evaluated in a packed bed reactor, and a 2D mass and heat transfer model were developed. Several agreements with experimental results were found, this was effective in optimising the reactors performance [14]. Several studies utilised $\mathrm{COMSOL}^{\circledR}$ to perform complex simulations and increase solution accuracy through mesh refinement and Finite Element (FE) methods. This is motivated by the need to couple experimental data with modelling outputs for validation purposes including operation, safety, and performance utilisation [12]. The carbonation process is affected not only by factors such as temperature, pressure, $\mathrm{pH}$, and aqueous solution flow rate, but also the Calcium Carbonate shape required. The crystal shape (calcite) is important while estimating the suitability of PCC for paper or paint production. The crystal shaped calcites and needle shaped aragonite are formed at $20-80^{\circ} \mathrm{C}$ [4].The key performance indicators for optimising the carbonation reactor such as, reactor design, sizing, construction material, environmental impacts, and economics have not been thoroughly presented. Therefore, the aim of this work is to investigate the effect of three key parameters (cooling jacket temperature, reactor wall material, and reactor geometry) on the heat transfer characteristics for an $89.72 \mathrm{~m}^{3}$ industrial scale carbonation reactor, to help achieve the optimum temperature quickly. This can have effects on the product quality, and help deciding on cooling water flow rate within the cooling jacket. The process involves varying the reactor geometry, the cooling jacket domain thickness, in addition to temperature of fluid reaction domain and cooling jacket domain. A conjugate heat transfer-model (including conduction and forced convection) that omits the cooling water flow, process kinetics, and agitation effects; to simplify the process, was designed. In addition, the focus is to objectively select appropriate operating temperature and construction material that can lower the system's capital and operating costs CAPEX/OPEX without compromising the carbonation process operational requirements. The objectives of this paper are:

(i) To evaluate the effect of various geometric parameters, i.e. reactor wall thickness taken as cooling region $(100,200$, and $300 \mathrm{~mm})$ and length-todiameter L/D ratios, on heat transfer characteristics.

(ii) To evaluate several construction materials in terms of temperature distribution profiles, costs of bare materials, and overall relative equipment cost, and;

(iii) To predict the performance of the cooling domain temperature that can simultaneously fulfil operating conditions of the carbonation reactor and lower the costs associated with process water cooling. This can be achieved by using COMSOL $^{\circledR}$ Multiphysics $5.2 \mathrm{a}$ software.

\section{MATERIALS AND METHODS}

\section{a) Generalised Carbonation Reactor Model}

The generalised heat balance used by the Heat Transfer module in $\mathrm{COMSOL}^{\circledR}$ Multiphysics $5.2 \mathrm{a}$ is the first law of 
Thermodynamics (principle of conservation of energy). The fundamental law is rewritten in terms of temperature $\mathrm{T}$ for a fluid (heat transfer module). The rate of heat transfer at steady state for a cooling area of a cooling jacket $\mathrm{A}_{\mathrm{j}}$ in $\mathrm{m}^{2}$ is taken as:

$$
Q=A_{j} \times U \times\left(T_{r}-T_{J}\right)
$$

Where $Q$ is the rate of heat transfer in Watts, $U$ is the overall heat transfer coefficient, while $T_{r}$ and $T_{J}$ are the reactiondomain and the jacket domain temperatures in ${ }^{\circ} \mathrm{C}$,respectively. Therefore, the heat balance that takes over the entire vessel body is given as [15]:

Stored Energy $=$ Generated Heat - Exchanged Heat

$$
m C_{p} \frac{d T_{r}}{d t}=\left(-\Delta H_{r}\right) \mathrm{R} V_{r}-A_{j} U\left(T_{r}-T_{J}\right)
$$

Where $\Delta \mathrm{H}_{\mathrm{r}}$ is the heat of reaction in $\mathrm{kJ} / \mathrm{mol}, \mathrm{R}$ is the reactor's radius, $V_{r}$ is the reactor's volume, and $C_{p}$ indicates the specific heat capacity at constant pressure in $\mathrm{J} / \mathrm{kg}$. ${ }^{\circ} \mathrm{C}$. The reactor is equipped with a cooling jacket to limit the temperature increase due to the exothermic nature of the reaction to avoid an explosion. The model is described by the energy balances for the reactor and the cooling jacket that is automatically set up in $\mathrm{COMSOL}^{\circledR}$ by selecting the proper application modes. The simulation is set up in the following steps: calculations to size the carbonation reactor were made based on initial material balance. Second, the geometry of the model was set up for an $89.72 \mathrm{~m}^{3}$ reactor vessel. Third, boundary conditions and initial values were set for the models, and last, the calculation domain meshed. The general model used for the carbonation reactor is illustrated in Figure 1 including boundary conditions (BC).

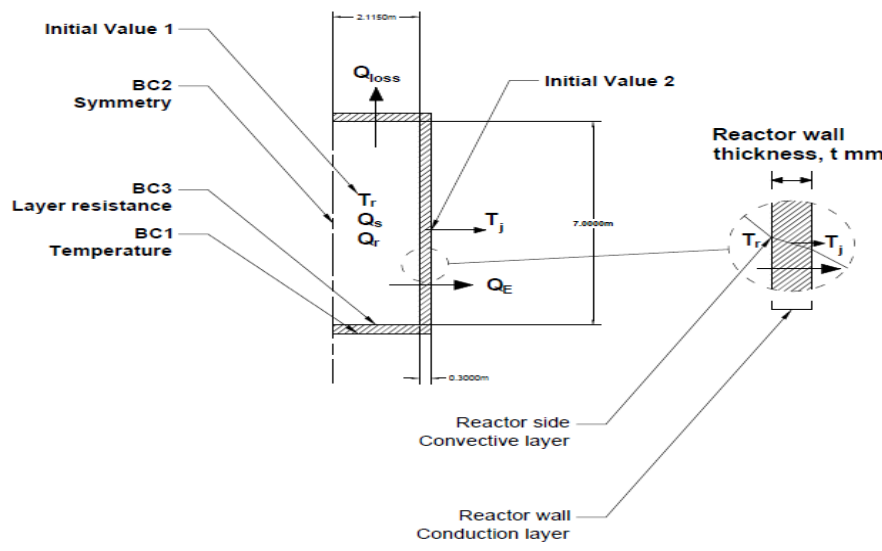

Figure 1: Carbonation reactor computational model. The model includes design dimensions, energy balance, and boundary conditions, $Q_{E}$ and $Q_{\text {loss }}$ represent exchanged and lost heat, respectively, while $Q_{s}$ indicates the heat source

\section{b) Geometry}

A single stirred tank was selected where the Calcium rich solution is loaded as a single charge and the $\mathrm{CO}_{2}$-containing flue gas is fed gradually [16]. Due to the exothermic nature of the carbonation process and subsequently limited solubility of $\mathrm{CO}_{2}$ in solution, a semi-flow jacketed reactor was chosen [10, $11,16]$. This is required to maintain a constant temperature of $50^{\circ} \mathrm{C}$ within the vessel. Also, economics were taken into consideration, where the carbonation reaction holds a relatively long residence and PCC production rate was moderate (820 kg per batch) [17].

A conventional external jacket that consists of an outer cylindrical vessel that surrounds part of the reactor's vessel was selected. The cooling fluid circulates in the space between the reactor wall and the jacket, where the heat is transferred through the reactor's wall [18]. The selection was based on heat transfer requirements, pressure rating, design, and pumping costs. A simple jacket with no baffles or agitation nozzles has lower heat transfer coefficients compared to dimple or spiral jackets with lowest CAPEX (pressure ratings $\leq 10$ Bar) $[17,18]$

Different shapes (Figure 2) were considered to show the effects of geometry on heat transfer rates throughout the reactor's body. Table I summarizes the models' dimensional parameters considered. The parameters considered involve:

- The length-to-diameter L/D ratio: varied over constant vessel volume to analyse different temperature distribution behaviours within the model, as illustrated in Table II. The ratio was varied according to experimental work on stirred tanks in literature [19-21].

- Wall thickness t mm: taken as spacing between the reactor's wall and the jacket used. Sinnott recommended a typical range of $50-300 \mathrm{~mm}$. The wall thickness was prioritised to aid the economic evaluation $[18,22]$.

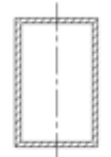

A

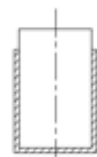

B

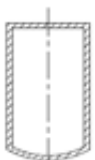

C

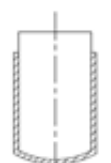

D

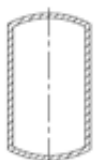

E

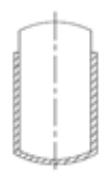

$\mathbf{F}$
Figure 2: Proposed geometry for the reactor's model namely from left to right; A, B, C, D, E, and F

Several assumptions to simplify this study were made regarding the carbonation reactor model, geometry, and other operating conditions which impact the heat transfer analysis:

1. The reaction media is perfectly mixed to give a homogeneous mixture. This is considered as the 
ISSN (online): 2581-3048

dimension of the cooling jacket depends on it [23].

2. The flue gas $\left(2.87 \% \mathrm{CO}_{2}\right.$ by mass $)$ is bubbled at steady state (no changes with time).

3. Excess flue gas leaves the reactor at the top without pressure changes in the vessel.

4. The reactor's volume is constant $\left(89.72 \mathrm{~m}^{3}\right)$.

5. The atmospheric pressure within the reactor's vessel is constant.

6. The total reactor's volume is filled with Ca-rich solution.

7. Corrosion allowance is incorporated with the wall thickness of chemical corrosion (i.e. $\mathrm{NH}_{4} \mathrm{Cl}$ ), $\mathrm{pH}$, temperature, stress corrosion (impurities), and erosion corrosion (agitation).

Table I

Dimensional Parameters Considered for Reactor's Model

\begin{tabular}{|l|l|l|l|}
\hline Parameter & $\begin{array}{l}\text { Recommended } \\
\text { Range }\end{array}$ & $\begin{array}{l}\text { Used } \\
\text { Values }\end{array}$ & Justification \\
\hline & & 1.37, & Values are kept \\
L/D ratio & $1.10-2.00$ & 1.55, & within \\
Unitless & & 1.92, & recommended \\
& & 2.00 & design range \\
\hline & & 100,200, & Higher values \\
Wall thickness & $50-300$ & 300 & are considered \\
mm & & & due to large \\
& & & reactor size \\
\hline
\end{tabular}

Table II

Dimensions Used for the Vessel's Geometry

\begin{tabular}{|l|l|l|l|l|}
\hline Volume $\mathbf{~ m}^{3}$ & $\mathrm{D}(\mathrm{m})$ & $\mathrm{R}(\mathrm{m})$ & $\mathrm{L}(\mathrm{m})$ & $\mathrm{L} / \mathrm{D}$ ratio \\
\hline \multirow{4}{*}{$\mathbf{8 9 . 7 2}$} & 4.36 & 2.18 & 6.00 & 1.40 \\
\cline { 2 - 5 } & 4.19 & 2.10 & 6.50 & 1.60 \\
\cline { 2 - 5 } & 1.04 & 2.02 & 7.00 & 1.70 \\
\cline { 2 - 5 } & 3.90 & 1.95 & 7.50 & 1.90 \\
\cline { 2 - 5 } & 3.78 & 1.89 & 8.00 & 2.10 \\
\hline
\end{tabular}

\section{c) Materials of Construction}

Three construction materials were used in the model to show effects on temperature distribution through the reactor's wall. Carbon Steel (CS, AISI 4340), Nickel (Ni), and Titanium (Ti) were selected. Carbon steel is the most commonly used material for construction, although it is not corrosion resistant, it is cheap [16, 24]. Nickel was chosen because of its ability to handle caustic alkali at higher temperatures compared to carbon steel. Titanium was used due to its resistance to halide solutions including wet chloride. Although it has high costs per tonne, it is widely used $[18,24]$.
Table III

Materials of Construction Used in the Reactor Model, With Related Physical Properties

\begin{tabular}{|c|c|c|c|c|c|c|}
\hline Material & $\begin{array}{l}\mathrm{k} \\
{[\mathrm{W} /} \\
\left(\mathrm{m} \cdot{ }^{\circ}\right. \\
\mathrm{C})]\end{array}$ & $\begin{array}{l}\rho \\
{[\mathrm{kg} / \mathrm{m}} \\
\left.\left.{ }^{3}\right)\right]\end{array}$ & $\mathrm{E}[\mathrm{Pa}]$ & $v$ & $\begin{array}{l}\mathrm{C}_{\mathrm{p}}[\mathrm{J} / \\
\left(\mathrm{kg} .{ }^{\circ}\right. \\
\mathrm{C})]\end{array}$ & Reference \\
\hline CS & 44.5 & 7850 & $205 \times 10^{9}$ & 0.28 & 475 & $\begin{array}{l}\text { COMSOL } \\
\text { materials library }\end{array}$ \\
\hline $\mathbf{N i}$ & 67.1 & 8900 & $207 \times 10^{9}$ & 0.31 & 456 & {$[25-28]$} \\
\hline $\mathbf{T i}$ & 16.0 & 4510 & $110 \times 10^{9}$ & 0.34 & 523 & {$[29,30]$} \\
\hline
\end{tabular}

\section{d) Heat Transfer in Fluids (ht) Module}

The purpose of the model was to calculate the 2DAxisymmetrical temperature distribution in the carbonation reactor model. Carbon steel, Nickel, and Titanium were modelled at different wall thicknesses (100, 200, and $300 \mathrm{~mm}$ ) and different operating temperatures for the reactor medium and the cooling domain, i.e. the jacket domain. Then, the dimensions were varied for each material, and a point probe $(1.5,0) \mathrm{m}$; to show temperature variation within the reaction domain close to the cooling jacket boundary (Figure 3).

$\mathrm{COMSOL}^{\circledR}$ solves its version of the heat equation to predict values for temperature in a defined point within the reacting medium and monitor temperature evolution over time. This was set to compare how temperature drops in the carbonation reactor model at the chosen probe point for different parameters combinations. The temperature characteristics of the model were controlled by conduction and forced convection. Therefore, the heat transfer in fluids module was used in the simulation for this study. The forced convection was represented by adding a boundary physics (convective layer resistance) between the solid and the fluid domains. This was done to overcome the difficulty of assigning a convective heat flux in a closed region, where an average value of $1 / 200\left(\left(\mathrm{~K} . \mathrm{m}^{2}\right) / \mathrm{W}\right)$ was deployed [18]. Temperatures of 15,25 , and $35^{\circ} \mathrm{C}$ were assigned to the cooling jacket domain to represent variations in the cooling water temperature, $T_{\mathrm{j}}$ used.

Temperatures of $50,60,70$, and $80^{\circ} \mathrm{C}$ were assigned interchangeably to the carbonation reaction medium to represent variations in the reaction temperature, $\mathrm{T}_{\mathrm{r}}$ according to literature. A heat source (inserted as total power in Watts) was added to reaction medium to represent the heat duty of the 
ISSN (online): 2581-3048

Volume 4, Issue 9, pp 19-30, September-2020 https://doi.org/10.47001/IRJIET/2020.409004

carbonation process, including the heat of reaction $\Delta \mathrm{H}_{\mathrm{r}}$. The value used was $319.80 \mathrm{KW}$ per batch of PCC produced $(820 \mathrm{~kg}$ PCC per batch) [31].

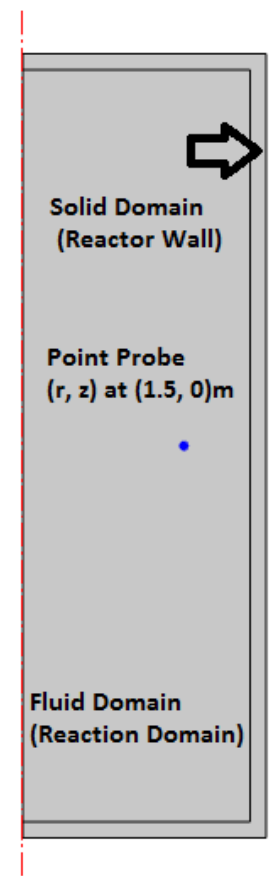

Figure 3: Graphics in $\mathrm{COMSOL}^{\circledR}$ showing solid and fluid domains

\section{e) Boundary Conditions}

The boundary conditions were set over the two domains (reactor medium and the cooling domain, i.e. the jacket domain) as follows:

- Initial value on solid domain (cooling jacket): Temperature, $\mathrm{T}=\mathrm{T}_{\mathrm{j}}\left(\right.$ ranged over 15,25 , and $\left.35^{\circ} \mathrm{C}\right)$.

- Initial value on fluid domain (reactor medium): Temperature, $\mathrm{T}=\mathrm{T}_{\mathrm{r}}$ (ranged over 50, 60, 70, and $80^{\circ} \mathrm{C}$ ). Temperature on outside boundary of the solid domain: Temperature $\mathrm{T}=\mathrm{T}_{0}$ (ambient temperature used $25^{\circ} \mathrm{C}$ ).

- Heat source in the fluid domain: Total power $\mathrm{P}_{\text {tot }}=$ 319800 Watts.

- Thermal resistance thin layer on inside boundary of the fluid domain: Thermal Resistance $R_{S}=1 / 200$ $(5 \times 10-3)\left(\left({ }^{\circ} \mathrm{C} \cdot \mathrm{m}^{2}\right) / \mathrm{W}\right)$.

The following simplifying assumptions were made to conduct this study in terms of the carbonation reactor and related operating conditions:

1. Perfect mixing within the reaction medium through agitation.

2. The system is perfectly insulated (i.e. $\mathrm{Q}_{\text {loss }}=0$ ).

3. Steady state heat transfer across the solid domain.

4. The fluid is incompressible; the Ca-rich solution and cooling water, i.e. density is constant.

5. The jacket temperature $T_{j}$ is constant. This is justified by smaller rise in water temperatures compared to the large flow rate [23].

6. The solid domain represents the cooling water used in terms of operating temperature.

\section{f) Mesh}

Meshing is defined as the discrete representation of the geometry considered, or elements over which differential equations can be iterated. The default physics-controlled mesh (tetrahedral mesh) was used. The element size was set to (extremely fine) at default, and the meshing sequence (including size and free tetrahedral mesh) was hidden. A higher number of elements were concentrated closer to the solid domain region, which was more than adequate to use for meshing. Thus, it was used to provide accurate results provided by the simplicity of the model's geometry.

\section{g) Time Dependent Study}

A transient simulation using a time dependent solver was used for computing the solution over time. The total time span considered was the total batch time $\left(t_{b}\right)$, which consists of filling time $\left(t_{f}\right)$, carbonation reaction time $\left(t_{r}\right)$, cooling time $\left(\mathrm{t}_{\mathrm{c}}\right)$, and emptying and cleaning time $\left(\mathrm{t}_{\mathrm{e}}\right)[4,17]$. Table IV illustrates the batch time distribution and total study time.

Table IV

Batch time distribution and total study time

\begin{tabular}{|l|l|}
\hline Operation & Time $(\min )$ \\
\hline Filling, $\mathbf{t}_{\mathbf{f}}$ & 30 \\
\hline Carbonation reaction, $\mathbf{t}_{\mathbf{r}}$ & 60 \\
\hline Cooling, $\mathbf{t}_{\mathbf{c}}$ & 30 \\
\hline Emptying and cleaning, $\mathbf{t}_{\mathbf{e}}$ & 30 \\
\hline Total batch/study time, $\mathbf{t}_{\mathbf{b}}$ & 150 \\
\hline
\end{tabular}

\section{RESULTS AND DISCUSSIONS}

\section{a) Effects of Geometry and Dimensional Parameters}

The heat transfer coefficient in the proposed model can be obtained from the overall thermal resistance; the convective resistance on the inner surface (i.e. layer between the fluid and solid domains), and the conductive resistance (i.e. vessel wall or cooling jacket).

$$
\frac{1}{U}=\frac{1}{h_{0}}+\frac{l}{k_{i} A}
$$

Where, $\mathrm{U}$ is the overall heat transfer coefficient $\left(\mathrm{W} /\left(\mathrm{m}^{2}\right.\right.$. $\left.\left.{ }^{\circ} \mathrm{C}\right)\right), 1 / \mathrm{h}_{0}$ is the convective resistance $\left({ }^{\circ} \mathrm{C} / \mathrm{W}\right)$, and $\mathrm{k}_{\mathrm{i}}$ is the thermal conductivity for material (i). The inner heat transfer coefficient was assumed constant, while the conductive resistance depends on the material used. From (Figure 4) below, for geometries where the solid domain (i.e. cooling 
ISSN (online): 2581-3048

Volume 4, Issue 9, pp 19-30, September-2020 https://doi.org/10.47001/IRJIET/2020.409004

jacket domain) entirely covers the fluid domain, the heat transfer rate is decreased.

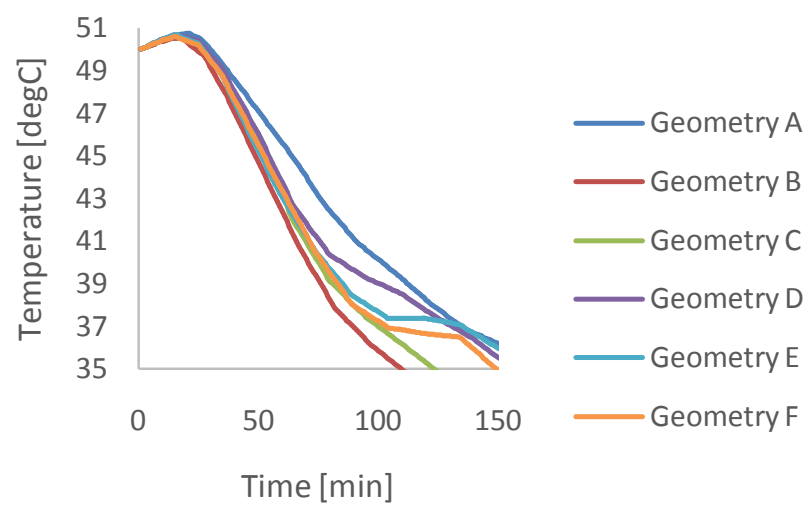

Figure 4: Temperature gradient for the geometries considered in the model

This is justified by the increased conductive thermal resistance due to increased surface area for the same wall thickness. The temperature increases slightly by $1-3^{\circ} \mathrm{C}$ in the first few minutes, where the cooling process is still not able to overcome the heat generated by the reaction within the reaction time.

An important parameter considered in this work is the wall thickness, taken as the spacing between the reaction medium and the jacket domain. It can be observed in (Figure 5), (Figure 6), and (Figure 7), that increasing the reactor's wall thickness makes the heat transfer increase, this gives the optimum required temperature i.e. $50 \pm 5^{\circ} \mathrm{C}$ within the reaction period.

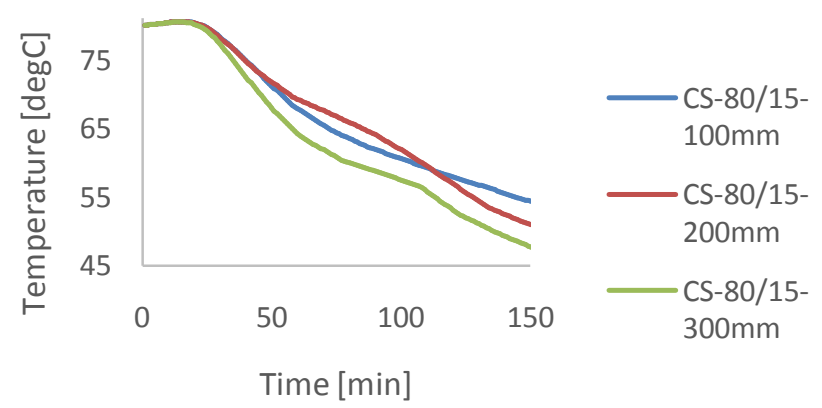

Figure 5: Comparison of different values of wall thickness for Carbon Steel AISI 4340

Assuming the fluid layer within the reactor's domain is motionless, and the wall thickness is the characteristic length; increasing the wall thickness results in increased Nusslet number $\mathrm{Nu}$ and consequently increased heat transfer under forced convection/conduction conditions. However, if the wall thickness is taken as a tube within which water flows; lower diameters enhance intensity, thinning of thermal boundary layers, and lowering heat transfer consequently. The following graphs compare three values for the wall thickness for all materials considered under same operating conditions $\left(\mathrm{T}_{\mathrm{r}}=\right.$ $80^{\circ} \mathrm{C}$ and $\mathrm{T}_{\mathrm{j}}=15^{\circ} \mathrm{C}$ ).

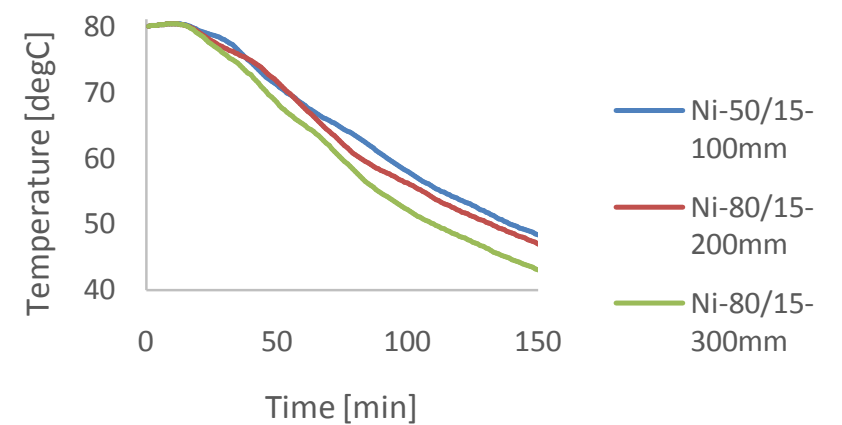

Figure 6: Comparison of different values of wall thickness for Nickel

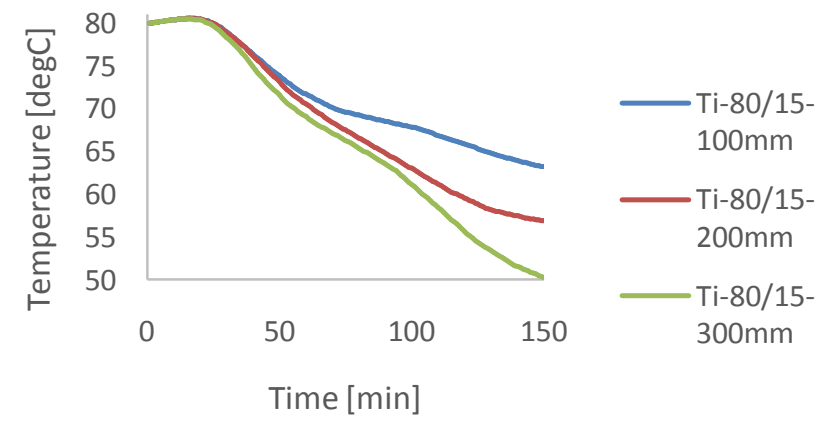

Figure 7: Comparison of different values of wall thickness for Titanium

Thermal conductivity of materials used, i.e. Carbon Steel, Nickel, and Titanium vary with temperature. The temperature decrease is shown in (Figure 8), (Figure 9), and (Figure 10), is compared for same temperature differences $(\Delta \mathrm{T}=65,55$, $\left.45^{\circ} \mathrm{C}\right)$, respectively.

The graphs confirm Fourier's Law of heat conduction, where Nickel and Carbon Steel have higher thermal conductivity compared to Titanium, as shown in Table III. Carbon Steel at lower temperature difference was more efficient in conducting heat for the same wall thickness. Although metal alloys have thermal conductivity that is usually much lower than pure metals; variation of thermal conductivity over certain temperature ranges can significant [32].

This explains the variation in Carbon Steel's heat transfer rates in graphs in (Figure 9) and (Figure 10). 
ISSN (online): 2581-3048

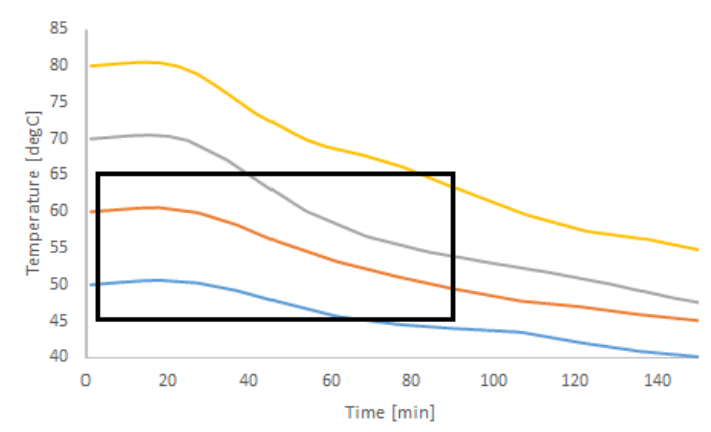

Figure 8: Temperature difference at different reaction temperatures, $T_{r}$ at $\mathbf{T}_{\mathrm{j}}=\mathbf{1 5}^{\circ} \mathrm{C}$

To maintain a constant temperature at $50^{\circ} \mathrm{C}$ within the fluid domain. An operating window between $50 \pm 5^{\circ} \mathrm{C}$ and 0 $60 \mathrm{~min}$ was considered. Although the reaction time $\mathrm{Tr}$ is $60 \mathrm{~min}$ starting after $30 \mathrm{~min}$ required for filling the reactor, Table 4 the model did not consider filling time before the reaction. This is justified by the experimental favorable temperature for $\mathrm{CaCO}_{3}$ precipitation under ambient working pressure. Carbon Steel and Nickel maintained an average temperature of 59.82 and $59.89^{\circ} \mathrm{C}$ respectively during reaction time compared to an average of $74.50^{\circ} \mathrm{C}$ for Titanium. In the case of $\mathrm{T}_{\mathrm{r}}=80^{\circ} \mathrm{C}$, the temperature difference was taken at $\mathrm{T}_{\mathrm{j}}=15,25$, and $35^{\circ} \mathrm{C}$ respectively, where Carbon Steel and Nickel, achieved almost similar temperature reduction percentages of $30 \%$ and $25 \%$ from the initial reaction temperature compared to $7 \%$ for Titanium during reaction time of $60 \mathrm{~min}$ for $\mathrm{t}=100 \mathrm{~mm}$.

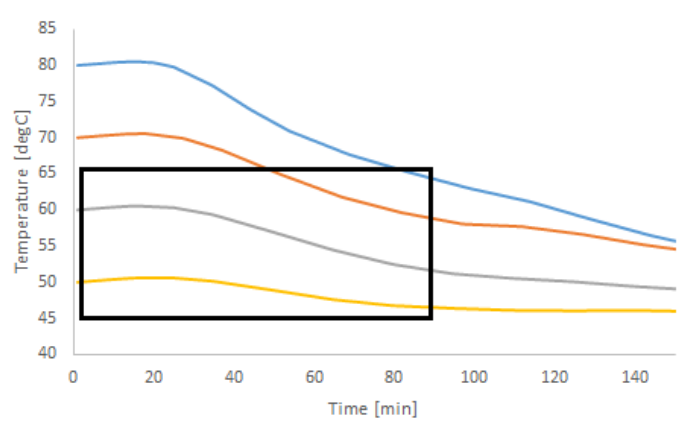

Figure 9: Temperature difference at different reaction temperatures, $T_{r}$ at $\mathbf{T}_{\mathbf{j}}=25^{\circ} \mathrm{C}$

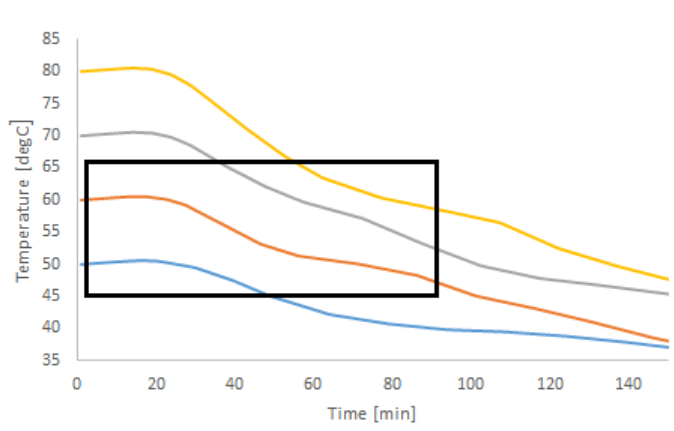

Figure 10: Temperature difference at different reaction temperatures, $T_{r}$ at $\mathbf{T}_{\mathrm{j}}=35^{\circ} \mathrm{C}$
To maintain a constant temperature at $50^{\circ} \mathrm{C}$ within the fluid domain. An operating window between $50 \pm 5^{\circ} \mathrm{C}$ and 0 $60 \mathrm{~min}$ was considered. Although the reaction time $\mathrm{Tr}$ is $60 \mathrm{~min}$ starting after $30 \mathrm{~min}$ required for filling the reactor, Table 4 the model did not consider filling time before the reaction. This is justified by the experimental favourable temperature for $\mathrm{CaCO}_{3}$ precipitation under ambient working pressure. Carbon Steel and Nickel maintained an average temperature of 59.82 and $59.89^{\circ} \mathrm{C}$ respectively during reaction time compared to an average of $74.50^{\circ} \mathrm{C}$ for Titanium. In the case of $\mathrm{T}_{\mathrm{r}}=80^{\circ} \mathrm{C}$, the temperature difference was taken at $\mathrm{T}_{\mathrm{j}}=15,25$, and $35^{\circ} \mathrm{C}$ respectively, where Carbon Steel and Nickel, achieved almost similar temperature reduction percentages of $30 \%$ and $25 \%$ from the initial reaction temperature compared to $7 \%$ for Titanium during reaction time of $60 \mathrm{~min}$ for $\mathrm{t}=100 \mathrm{~mm}$. Titanium was not able to maintain required operating temperature within carbonation reaction time due to low thermal conductivity versus the high heat source within the fluid domain that creates higher temperature differences in all cases considered. However, only Carbon Steel AISI 4340 and Nickel satisfied required operating temperature window at the end of the reaction period when the cooling jacket (solid domain) was maintained at $\mathrm{T}_{\mathrm{j}}=15^{\circ} \mathrm{C}$, (Figure 8) and (Figure 9). Low heat transfer rates can due to the motionless fluid domain assumed within the reactor vessel.

\section{b) Effects of Cooling Jacket Temperature $\mathbf{T}_{\mathbf{j}}$}

The effect of the solid domain temperature is compared for a wall thickness of $300 \mathrm{~mm}$, for Carbon Steel AISI 4340, and different reaction temperatures $\operatorname{Tr}$ to observe the effect of temperature differences on heat transfer rates in each case. By comparing (Figure 11), (Figure 12), and (Figure 13) below, it can be seen that heat transfer rate is increased with increased temperature difference across the heat transfer layer in the reactor's model. Operating the jacket at ambient temperature can maintain a temperature of $50 \pm 5^{\circ} \mathrm{c}$ during reaction period if the exothermic reaction is maintained lower than $70^{\circ} \mathrm{C}$. As shown in (Figure 12), the required operating temperature was not achieved when the reaction temperature was $80^{\circ} \mathrm{C}$.

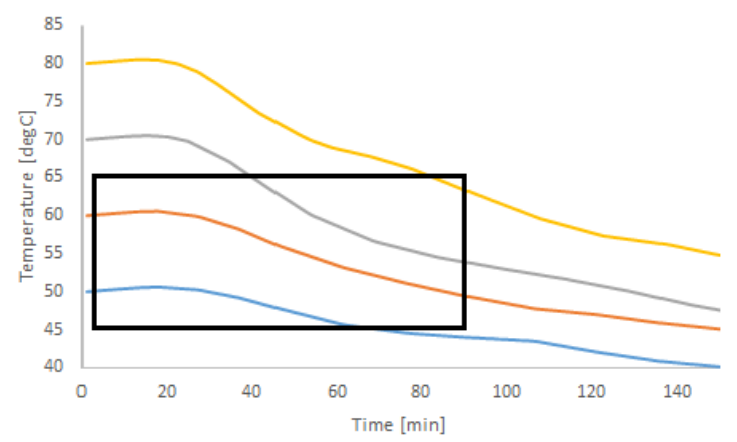

Figure 11: Temperature difference at different reaction temperatures, $T_{r}$ at $\mathbf{T}_{\mathbf{j}}=15^{\circ} \mathrm{C}$ 
ISSN (online): 2581-3048

Volume 4, Issue 9, pp 19-30, September-2020 https://doi.org/10.47001/IRJIET/2020.409004

Although a final value of 54.70 was achieved by the end of the batch time, this is not up to the carbonation process operating temperature requirement.

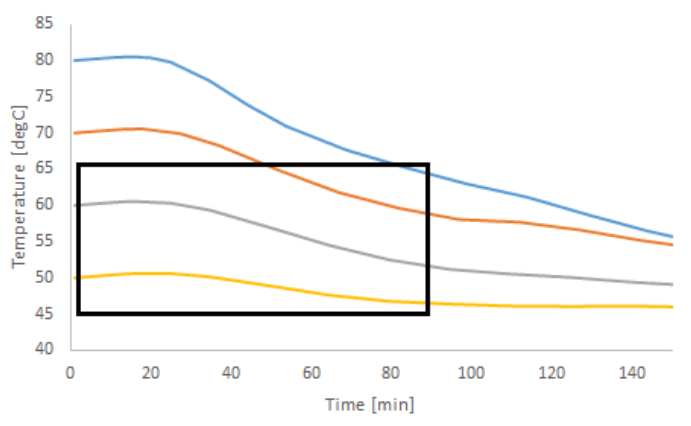

Figure 12: Temperature difference at different reaction temperatures, $T_{r}$ at $\mathbf{T}_{\mathbf{j}}=25^{\circ} \mathrm{C}$

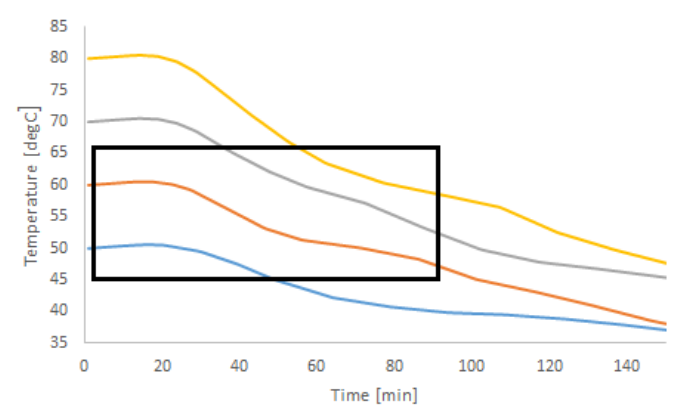

Figure 13: Temperature difference at different reaction temperatures, $T_{r}$ at $\mathbf{T}_{\mathbf{j}}=\mathbf{3 5}^{\circ} \mathrm{C}$

Operating the cooling jacket at a lower temperature than ambient would be unnecessary for this case; because the heat source taken at the fluid represents the heat duty for the whole carbonation process and not the heat of reaction.

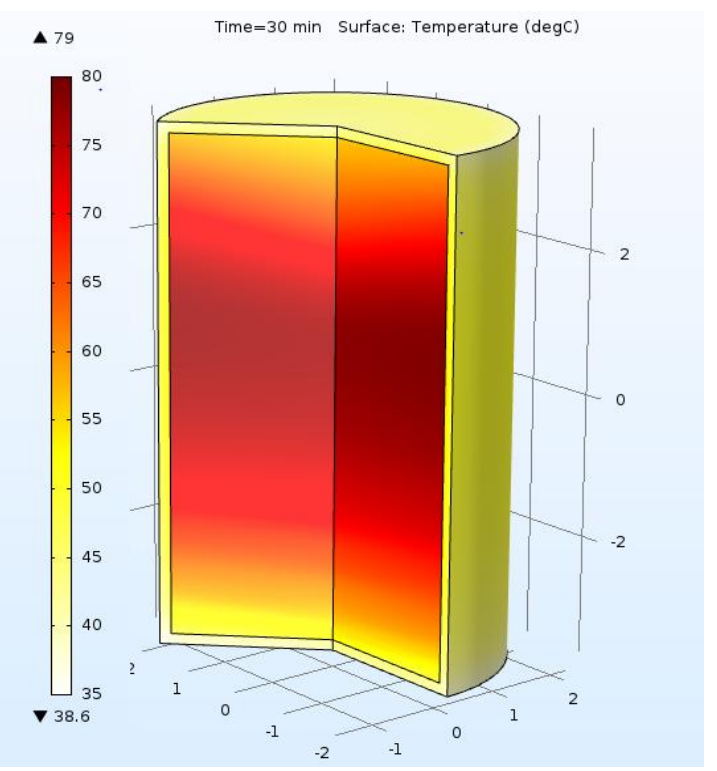

Figure 14: 3D temperature distribution in the primary model after 30min at an initial temperature of $35^{\circ} \mathrm{C}$ and $80^{\circ} \mathrm{C}$ for the cooling and reaction domains, respectively $(t=300 \mathrm{~mm})$
However, further experimental work and modeling is required to confirm this. (Figure 14) illustrates temperature distribution in a $3 \mathrm{D}$ plot after $30 \mathrm{~min}$.

\section{c) Economic Study}

An economic evaluation was conducted in this study to further investigate the effect of certain parameters. Capital costs of materials, and capital purchased costs of the carbonation vessel were studied at proposed wall thickness values. This is significant to further optimise the overall performance of the carbonation process. The volume of the vessel material was used to evaluate Carbon Steel, Nickel, and Titanium costs to show variations in terms of wall thickness. The densities $\rho$ and design stresses were also considered, as the material quantity is highly dependent on them [18]. A factorial method was utilized to obtain the purchased costs at different vessel capacities in $\mathrm{m}^{3}$ as recommended by Towler and Sinnot [24].

In (Figure 15) and (Figure 16) the materials cost (in million British pounds) considered is proportional to the reactor wall thickness as expected. Titanium and Nickel costs increased by $68.34 \%$ and $68.08 \%$ respectively, when wall thickness was tripled $(300 \mathrm{~mm})$, which is relatively expensive compared to Carbon Steel with a $66.67 \%$ increase. Table Vcompares the three materials by cost rating factors relative to that of Carbon Steel.

Table V

Relative cost ratings for proposed construction materials

\begin{tabular}{|l|l|l|l|l|}
\hline Material & $\rho,\left[\mathrm{kg} / \mathrm{m}^{3}\right]$ & $\sigma d,\left[\mathrm{~N} / \mathrm{mm}^{2}\right]$ & $\begin{array}{l}\text { Cost, } \\
{[£ / \mathrm{kg}]} \\
(2015)\end{array}$ & $\begin{array}{l}\text { Cost } \\
\text { Rating }\end{array}$ \\
\hline $\begin{array}{l}\text { CS (AISI } \\
\mathbf{4 3 4 0})\end{array}$ & 7850 & 1792 & 0.38 & 1 \\
\hline $\mathbf{N i}$ & 8900 & 500 & 8.02 & 87 \\
\hline $\mathbf{T i}$ & 4510 & 500 & 25.07 & 137 \\
\hline
\end{tabular}

The Carbon Steel finished equipment capital cost is 94.80-96.30\% higher than material cost; this is considered unusual, as the relative cost of the finished equipment is commonly lower than relative bare material cost, unless certain fabrication processes are required [18]. Proper economic analysis is required to allow for comparison of different alternatives. Together with the heat transfer ability of each material, maintaining the favourable operating temperature should include economic considerations of material quantities i.e. wall thickness in addition to total installation costs, maintenance, and service life [16]. In this case installing a Carbon Steel reactor may prove to be more 
ISSN (online): 2581-3048

Volume 4, Issue 9, pp 19-30, September-2020

https://doi.org/10.47001/IRJIET/2020.409004

economic, rather than the more resistant and expensive Nickel and Titanium alloys. This is strongly supported by the simplicity of the carbonation reactor, low fabrication costs, and safety and environmental considerations, where vessel failure would not cause hazardous effect.

\section{Materials of construction cost in MMf (2015) for wall thickness values}

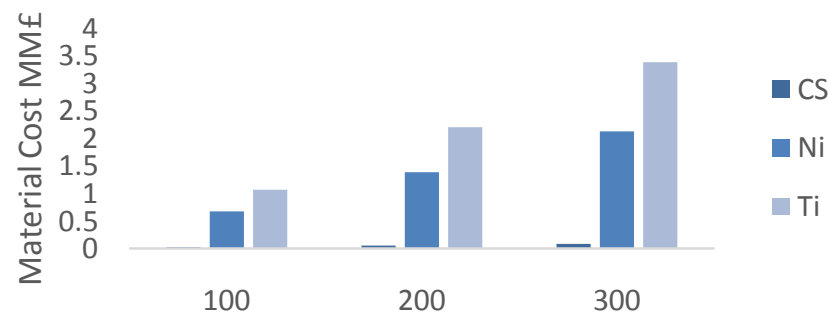

Reactor Wall Thickness mm

Figure 15: Bare materials costs based on vessel mass at different wall thickness values

Purchased Equipment Cost PEC for different materials and capacity values

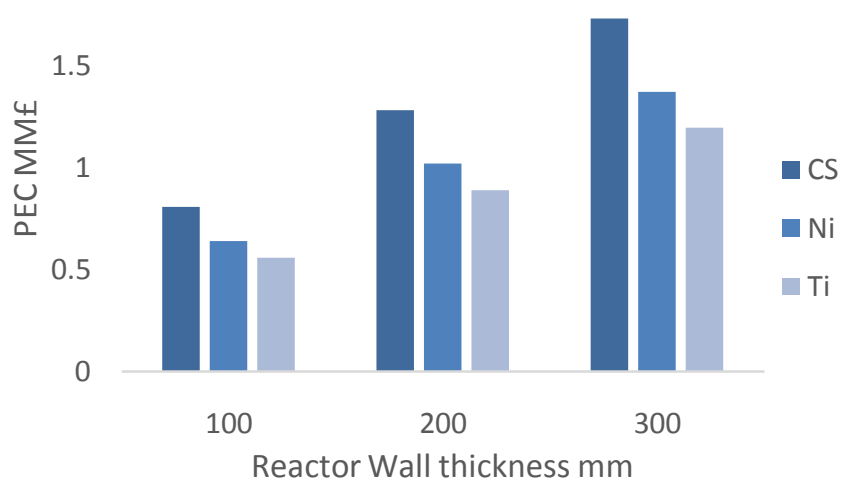

Figure 16: Purchased equipment costs based on vessel capacity in $\mathbf{m}^{3}$ for different wall thickness values

The cooling water costs were explored as costs required raising cooling jacket temperature by $1^{\circ} \mathrm{C}$. This enables estimation of varying cooling water operating costs when the temperature difference in known. In this study, the volume of water was assumed to be equal to the material volume at different thickness values $(100,200$, and 300). This was taken to match the assumption made, that all solid domain was taken as the cooling water region. The graph in (Figure 17) summarizes costs for four selected temperature differences, where increased temperature differences result in increased operating costs. Utilizing water at ambient temperature 20- $25^{\circ} \mathrm{C}$ would result in lower temperature differences ranging between $10-18^{\circ} \mathrm{C}$.

\section{Comparison of cooling water operating costs requirements at temperature differences}

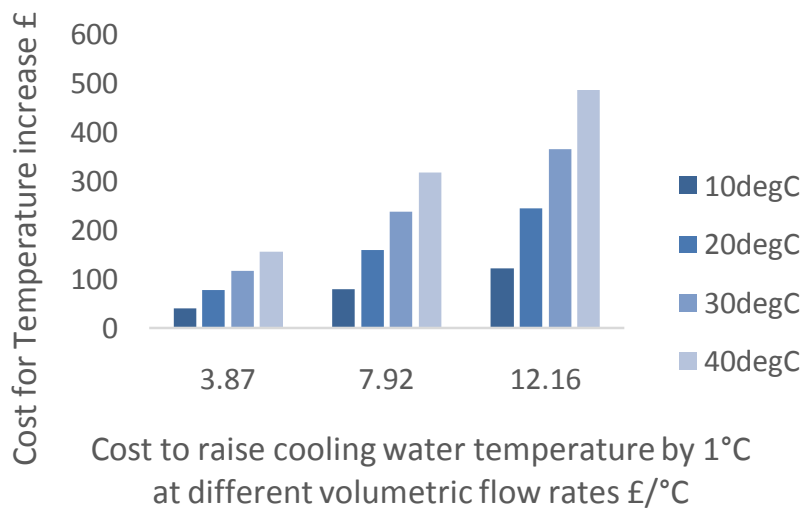

Figure 17: Cooling water OPEX in $£ /{ }^{\circ} \mathrm{C}$ for temperature differences

This can reduce cooling water operating costs for the carbonation reactor by $25-50 \%$ for each $10^{\circ} \mathrm{C}$ as temperature difference. However, more work is required to specify costs of electric power, pumping power, and make-up water requirements. Also, detailed design and experimental and/or pilot scale works are significant to check that the system has sufficient capacity to meet the operating temperature requirements over a range of ambient conditions and/or a sensitivity analysis.

\section{d) Model Validation}

Error or uncertainty analysis was not considered in this study. However, validation of modeling results is considered in terms of assumptions and input parameters. This can be achieved through comparing outcomes to more detailed simulation models. In an experimental study that presented heat transfer of metallic Nano-fluids in an agitated heat exchanger examined the effects of agitator speed and tube diameter. As the channel inner diameter increased, the boundary layer is developed and heat transfer is reduced. This is true when flow rate of cooling water is considered. However, in this study, the cooling jacket domain is presented by a solid metal, therefore conductive heat transfer applies and thermal conductivity and temperature difference are more prevailing. This shows reasonable agreement with modeling results despite the simplifying assumptions.

Effects of thermal conductivity and temperature differences across the solid domain were confirmed by heat conduction in solids. This depends on the geometry of the medium, thickness, materials used, and temperature 
difference. To demonstrate that the present model is a reasonable representation of the actual system, real system measurements are most reliable and preferred validation method. An experiment is required to analyze transient cooling of the Ca-rich solution at different agitator speeds. Also, analysis of steady state heat transfer at different flow rates of cooling water is important. This means including several factors that can have a significant impact on heat transfer characteristics including impeller speed, baffles effects on geometry, and cooling water flow rate. In addition, comparing experimental values of overall heat transfer coefficients with correlations in literature should be explored [33].

Utilities including a centrifugal pump, a flow meter, thermocouples, and pressure gauges are required for the experiment. A tank or vessel with a surrounding jacket can be the main part of the experiment. Baffles for vortex formation reduction are essential for improved agitation and heat transfer rates. (Figure 18) illustrates the arrangement proposed for a simple laboratory experiment on heat transfer in an agitated vessel [34].

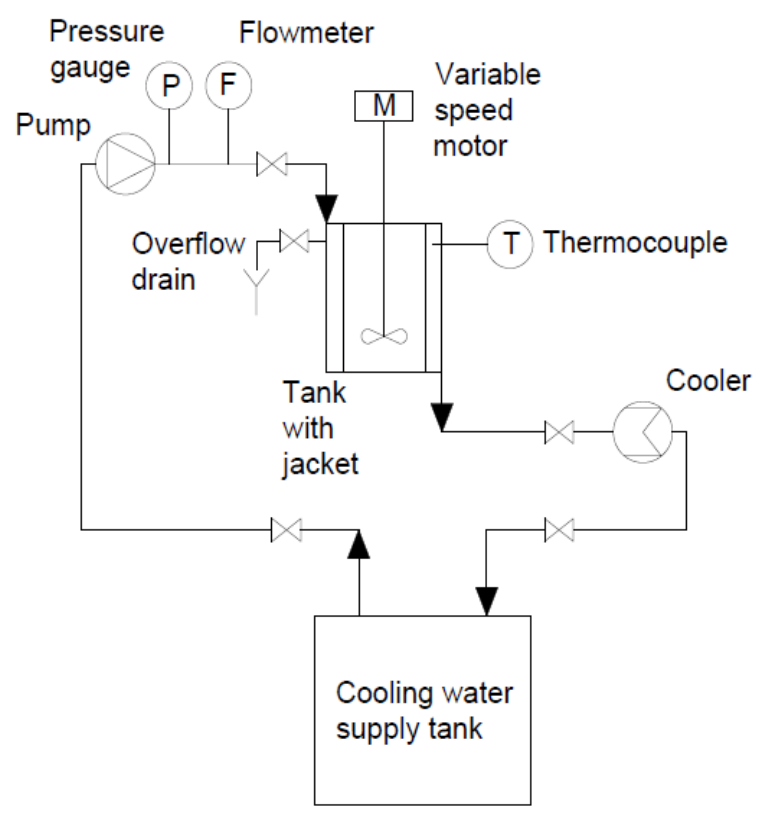

Figure 18: Schematic diagram of the proposed experiment

\section{CONCLUSION}

A model was carried out on an industrial scale carbonation reactor vessel $\left(89.72 \mathrm{~m}^{3}\right)$. The effects of vessel geometry (6 different shapes), wall thickness (100, 200, and $300 \mathrm{~mm})$, cooling jacket temperature $\left(15,25\right.$, and $\left.35^{\circ} \mathrm{C}\right)$, and construction material (Carbon Steel AISI 4340, Nickel, and Titanium) on temperature distribution across the vessel wall were analyzed and discussed. It can be concluded that cooling jackets that partially over the vessel body with a wall thickness of $100 \mathrm{~mm}$ (including corrosion allowance), and cooling water at ambient temperature $\left(20-25^{\circ} \mathrm{C}\right)$ can achieve the required optimal operating temperature i.e. $\left(50 \pm 5^{\circ} \mathrm{C}\right)$ within the reaction time (60min of total $60 \mathrm{~min}$ batch time). The results show that carbon steel AISI 4340 (£0.03 million) is more economic than Nickel ( $£ 0.68$ million) and Titanium (£1.08 million) in terms of bare material cost at a wall thickness of $100 \mathrm{~mm}$. Also, utilising water at ambient temperature result in lowering OPEX by $25-50 \%$ for each $10^{\circ} \mathrm{C}$, without considering power and make-up water costs.

\section{ACKNOWLEDGEMENT}

Technical support for this study was provided by the Department of Chemical and Environmental Engineering, in the Faculty of Engineering at University of Nottingham.

\section{REFERENCES}

[1] D.R.Han, H.Namkung, H.M Lee, D.G. Huh, and H.T.Kim, "CO2 sequestration by aqueous mineral carbonation of limestone in a supercritical reactor", Journal of Industrial and Engineering Chemistry, vol.21, pp.792-796, 2015.

[2] S.Y.Pan, H.-L.Liu, E.E.Chang, H.Kim, Y.-H.Chen, and P.-C. Chiang, "Multiple model approach to evaluation of accelerated carbonation for steelmaking slag in a slurry reactor", Chemosphere, vol.154, pp.63-71,2016.

[3] N.L.Ukwattage, P.G.Ranjith, and X.Li, "Steelmaking slag for mineral sequestration of carbon dioxide by accelerated carbonation", Measurement, vol.97, pp.15-22, 2017.

[4] H.P. Mattila and R.Zevenhoven, "Production of Precipitated Calcium Carbonate from Steel Converter Slag and Other Calcium-Containing Industrial Wastes and Residues", Advances in Inorganic Chemistry, vol. 66, pp. 347-384, 2014.

[5] Worldsteel.org. 2017. "World Steel in Figures 2017 Now Available", [online] Available at: https://www.worldsteel.org/media-centre/pressreleases/2017/world-steel-in-figures-2017.html, [Accessed 25 August 2017], 2017.

[6] E.J.Berryman, A.E.Williams-Jones, and A.A.Migdisov, "Steel slag carbonation in a flowthrough reactor system: The role of fluid-flux", Journal of Environmental Sciences, vol. 27, pp. 266275, 2015.

[7] E. E.Chang, T.-L.Chen, S.-Y.Pan, Y.-H. Chen, and P.-C.Chiang, "Kinetic modeling on $\mathrm{CO} 2$ capture using basic oxygen furnace slag coupled with cold- 
rolling wastewater in a rotating packed bed", Journal of Hazardous Materials, vol. 260, pp. 937-946, 2013.

[8] J.Bang, Y.Jang, W.Kim, K.Song, C.Jeon, S.Chae, S.Lee, S.Park, and M.Lee, "Precipitation of calcium carbonate by carbon dioxide microbubbles", Chemical Engineering Journal, vol. 174, no1, pp.413-420, Oct. 2011.

[9] S.Teir, T.Kotiranta, J.Pakarinen, and H.-P.Mattila, "Case study for production of calcium carbonate from carbon dioxide in flue gases and steelmaking slag", Journal of CO2 Utilization, vol. 14, pp. 37-46, 2016.

[10] T.Hosseini, M.Daneshpayeh, C.Selomulya, N.Haque, and L.Zhang, "Chemical kinetic modeling and parameter sensitivity analysis for the carbonation of $\mathrm{Ca} 2+$ and $\mathrm{Mg} 2+$ under ambient conditions", Hydrometallurgy, vol. 167, pp. 141-152, 2017.

[11] H.P.Mattila, H.Hudd, and R.Zevenhoven, "Cradle-togate life cycle assessment of precipitated calcium carbonate production from steel converter slag", Journal of Cleaner Production, vol. 84, pp. 611-618, 2014.

[12] N.Xoubi, and A.Y Soliman, "Neutronic modeling and calculations of the ETRR-2 MTR reactor using COMSOL multiphysics code", Annals of Nuclear Energy, vol. 109, pp. 667-674, 2017.

[13] D.Chandler,G. I.Maldonado,R. T.Primm, and J. D.Freels, "Neutronics modeling of the High Flux Isotope Reactor using COMSOL", Annals of Nuclear Energy, vol. 38, pp. 2594-2605, 2011.

[14] M.Gaeini, R.Wind, P.A.J.Donkers, A.Zondag, and C.C.M.Rindt, "Development of a validated 2D model for flow, moisture and heat transport in a packed bed reactor using MRI experiment and a lab-scale reactor setup". International Journal of Heat and Mass Transfer, vol. 113, pp. 1116-1129, 2017.

[15] S.Krämer, and R. Gesthuisen, "Simultaneous estimation of the heat of reaction and the heat transfer coefficient by calorimetry: estimation problems due to model simplification and high jacket flow ratestheoretical development", Chemical Engineering Science, vol. 60, pp. 4233-4248, 2005.

[16] R.H.Perry, and D.W.Green, Perry's Chemical Engineers' Handbook, McGraw-Hill, 2008.

[17] H.Silla, Chemical Process Engineering: Design and Economics, Taylor \& Francis, 2003.

[18] R.K.Sinnott, Chemical Engineering Design: Chemical Engineering, Elsevier Science, 2005.

[19] B.O.Hasan, "Experimental study on the bubble breakage in a stirred tank. Part 1. Mechanism and effect of operating parameters", International Journal of Multiphase Flow, vol. 97, pp. 94-108, 2017.
[20] D.Gu, Z.Liu, F.Qiu, J.Li, C.Tao, and Y.Wang, "Design of impeller blades for efficient homogeneity of solid-liquid suspension in a stirred tank reactor", Advanced Powder Technology, vol. 28, no. 10, pp. 2514-2523, Oct.2017.

[21] M.S.Soliman, S.A.Nosier, M.Hussein, G.H.Sedahmed, and A. A. Mubarak, "Mass and heat transfer behavior of a new heterogeneous stirred tank reactor with serpentine tube baffles", Chemical Engineering Research and Design, vol. 124, pp. 211221, 2017.

[22] G.Towler, and R.Sinnott, Chemical Engineering Design. Amsterdam: Butterworth-Heinemann, 2012.

[23] D.G.Peacock, and J.F.Richardson, Chemical Engineering, Volume 3: Chemical and Biochemical Reactors and Process Control, Elsevier Science, 2012.

[24] G.Towler, and R.Sinnott, Chapter 7 - Capital Cost Estimating. Chemical Engineering Design (Second Edition). Boston: Butterworth-Heinemann, 2013.

[25] D.O. Kipp, Metal Material Data Sheets. Mat Web, LLC, Division of Automation Creation, Inc, 2017.

[26] M.Schwartz, Soldering - Understanding the Basics. ASM International, Feb. 2014

[27] A.Cottrell, Introduction to Metallurgy (2nd Edition), Maney Publishing for IOM3, the Institute of Materials, Minerals and Mining.

[28] A.V.Pocius, Adhesion and Adhesives Technology An Introduction (3rd Edition), Hanser Publishers.

[29] M.J. Neale, Tribology Handbook (2nd Edition). Elsevier.

[30] J.G. Kaufman, Titanium Alloy Database, Knovel.

[31] H.P.Mattila, I.Grigaliūnaite, and R.Zevenhoven, "Chemical kinetics modeling and process parameter sensitivity for precipitated calcium carbonate production from steelmaking slags", Chemical Engineering Journal, vol. 192, pp. 77-89, 2012.

[32] Y.A.Cengel, Heat Transfer: A Practical Approach, McGraw-Hill, 2007.

[33] M.Khoshvaght-Aliabadi, M.Nouri, O.Sartipzadeh, and M.Salami, "Performance of agitated serpentine heat exchanger using metallic nanofluids", Chemical Engineering Research and Design, vol. 109, pp. 5364, 2016.

[34] N.N.Nassar, and A.K.Mehrotra, "Design of a laboratory experiment on heat transfer in an agitated vessel", Education for Chemical Engineers, vol. 6, pp. 83-89, 2011. 


\section{AUTHOR'S BIOGRAPHY}

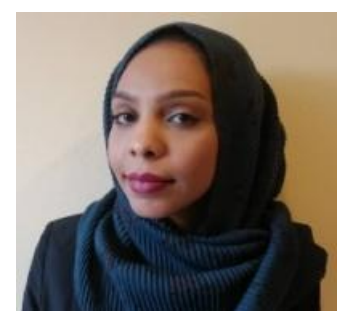

Yousra H. M. Elzaki is a performance driven environmental engineer with denoted experience in the field of agricultural-based environmental engineering and WASH services. Yousra holds an M.Sc. in environmental engineering from the University of Nottingham. Ms. Elzaki is enthusiastic about sustainable development and process design that contribute in solving environmental problems. She is interested in advocacy and aims to link academia and professional expertise to lead action on environmental issues.

\section{Citation of this Article:}

Yousra Hayder Mohmmed Elzaki, "Optimisation of Carbonation Reactor Design Using Multiphysics Models for Precipitated Calcium Carbonate PCC Production" Published in International Research Journal of Innovations in Engineering and Technology - IRJIET, Volume 4, Issue 9, pp 19-30, September 2020. https://doi.org/10.47001/IRJIET/2020.409004 